\title{
A New Preparative Method for trans Alkenols*
}

\author{
ALF CLAESSON
}

Department of Organic Chemistry, Faculty of Pharmacy, University of Uppsala, Box 574, S-751 23 Uppsala, Sweden

Four 4-alken-1-ols $(3 b-f)$ have been prepared in a new stereoselective mode, which involves treatment of 5-(tetrahydro-2-pyranyloxy)-3penten-1-ols and the corresponding 5-alkoxy derivatives $(2 b-f)$ with lithium aluminium hydride in refluxing dioxane. The method is an extension of a reported analogous reaction of 4-alkoxy-2-buten-1-ols, which gives rise to 3 alken-1-ols. 3-Penten-1-ol is prepared here using this latter method. Disubstituted olefinic alcohols are formed in a minimum trans:cis ratio of 97:3. The reaction is proposed to have a transition state with strong carbanion character.

According to our recent publication, ${ }^{1}$ 3-alken1-ols can be prepared in good yields using readily available acetylenes as key intermediates ( $c f$. Scheme $1, n=0$ ). Furthermore, this reaction is stereoselective as shown by the formation of 3-hepten-1-ol in a trans:cis ratio of $97: 3$ and $\sim 100 \%$ pure 2-methyl-trans-4-octen-2-ol. In the present paper we have included the preparation of trans-3-penten-1-ol, to further verify the

* Allenes and Acetylenes VII. Part VI: Ref. 8. high stereoselectivity in the formation of 3 alken-1-ols. Trisubstituted olefins, however, are formed with poor stereoselectivity, the ratio of trans:cis beeing $3: 2$ in the typical case.

We here wish to report on an extension of this new synthetic method to the stereoselective preparation of trans-4-alken-1-ols starting with the acetylenic derivatives $1 b-f$ (cf. Scheme 1, $n=1$, and Table 1).

\section{RESULTS}

The starting acetylenes $1 a-f$ were obtained using standard procedures. Their preparation has been described elsewhere. ${ }^{8,23}$

The preparations of trans-3-penten-1-ol $(3 a)$ and the 4-alkenols $3 b-f$ from the acetylenes $1 a-f$ were carried out as described for 3 alkenols in our previous work ${ }^{1}$ (cf. Scheme 1 and Table 1). Partial hydrogenation of $1 a-f$ in hexane gave the corresponding alkoxy- or Thp-oxy-alkenols $(2 a-f)$ which without prior

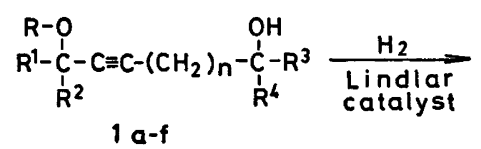
$1 a-f$<smiles>[R]OC1([R])OP[R]1[H]</smiles>

$2 a-f$

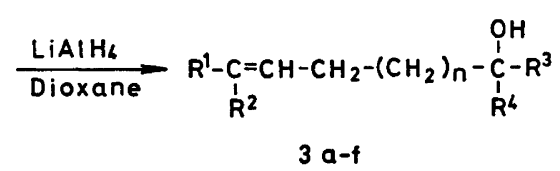

Scheme $t$
$R=$ Thp or $a|k y|$
$n=0$ or 1

Acta Chem. Scand. B 28 (1974) No. 9 


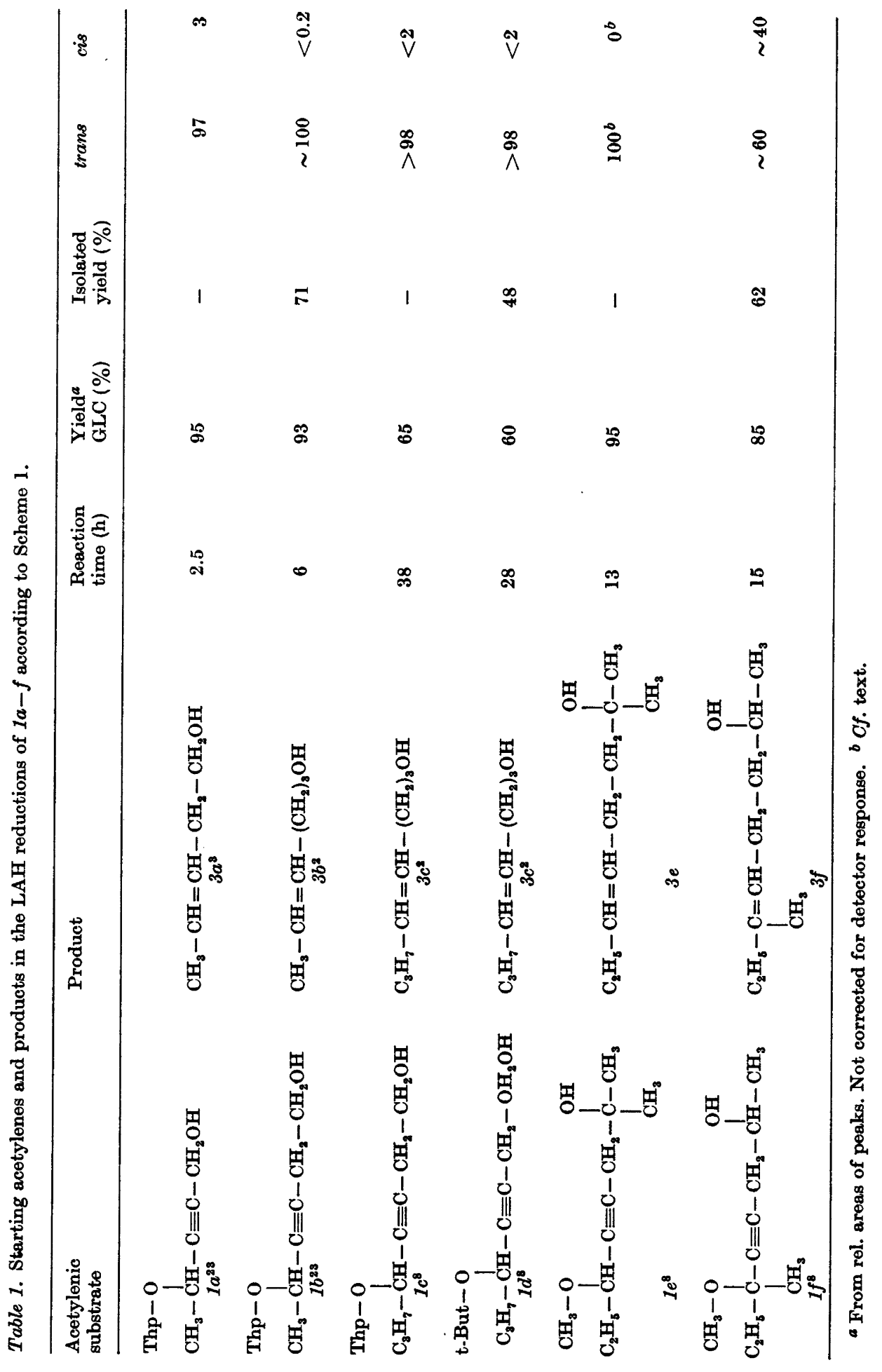

Acta Chem. Scand. B 28 (1974) No. 9 
purification were allowed to react with lithium aluminium hydride (LAH) in refluxing dioxane.

The cis:trans ratios of the so obtained alkenols $3 a-e$ were determined on GLC using 3 or $6 \mathrm{~m}$ long columns containing $20 \%$ Carbowax $20 \mathrm{M}$ or SE-30. In all cases, except that of $3 e$, the corresponding cis alkenols were prepared independently to allow a correct assignment of the cis:trans ratios. cis-4-Hexen-1-ol, ${ }^{2}$ cis-3-penten1-ol, ${ }^{3}$ and cis-4-octen-1-ol were obtained through partial hydrogenation of the corresponding 4alkyn-1-ols. ${ }^{2-4}$

The cis and trans-4-hexen-1-ols separated on a $6 \mathrm{~m}$ Carbowax $20 \mathrm{M}$ column with a ratio of retention times cis:trans $=1.09$ at $25 \mathrm{~min}$. Other authors have reported clean separation on PEG$1500 .^{5}$ In contrast, the isomers of 4-octen-1-ol could not be completely separated on a $6 \mathrm{~m}$ Carbowax column and there was no separation on a $3 \mathrm{~m} \mathrm{SE}-30$ column. The ratio of retention times for the cis and trans isomers was 1.06 at 25 min on Carbowax. However, the separation attained allowed an estimation accurate enough to establish the maximum content of the cis isomer indicated in the Table 1. No difference in the cis:trans ratios of 4-octen-1-ol from different starting materials (1c and $1 d$ ) could be detected.

The tertiary alcohol $3 e$ was homogeneous on all the above columns even at retention times of about $1 \mathrm{~h}$.

3-Penten-1-ol (3a) contained $3 \%$ of the cis isomer, which is the same percentage, that we have reported ${ }^{1}$ for 3-hepten-1-ol prepared in the same way. $\left(R_{\mathrm{t}}\right.$ cis: $R_{\mathrm{t}}$ trans $=1.14$ at $22 \mathrm{~min}$ on a $3 \mathrm{~m}$ Carbowax column).

We have made use of the different chemical shifts in NMR of cis and trans methyl groups in trisubstituted olefins ${ }^{\circ}$ in determining the isomer composition of some 4-methyl-3-alken-1-ols. ${ }^{1}$ From the $100 \mathrm{MHz}$ NMR spectrum of $3 f$, it could be estimated that the trans:cis ratio was $3: 2$, in spite of some interference from methylene protons at $\delta \mathbf{1 . 5 0}$.

\section{DISCUSSION}

The above formations of 3- and 4-alkenols formally constitute a type of allylic rearrangement ( $\mathrm{S}_{\mathrm{N}} 2^{\prime}$ reaction). However, mechanistically the question arises as to what degree the attack by hydride on the double bond and the expulsion of alkoxide are concerted.
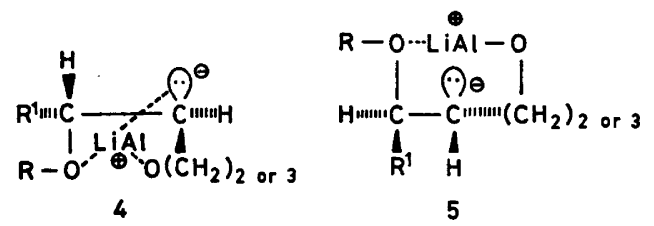

There are essentially two main reaction mechanisms. (i) The first is a normal concerted reaction with a more or less synchronous attack by hydride and allylic rearrangement in the transition state. (ii) The reaction may also, in the extreme case, proceed in two steps via carbanions, that might be pictured as 4 or 5 , both of them affording trans olefins upon decomposition.

When considering the most likely mechanism one should have in mind that the double bond of allylic alcohols having a carbanion stabilizing group at C-3 is easily reduced by LAH with formation of an organometallic bond at this position. The cinnamyl alcohol system is particularly well investigated.?

Therefore, in the present case it seems reasonable to assume that attack by hydride on the double bond is well ahead of the expulsion of the alkoxide group, leading to a transition state having strong carbanion character. The reaction might possibly proceed via organometallic intermediates, which then is especially conceivable, when the poorly leaving $t$-butoxy group is substituted.

We have not been able to detect a hydrolysis product derived from carbanions such as 4 and 5 , which is not surprising in view of their expected instability. In an analogous reaction we have allowed acetylenic derivatives of type $1 b-f$ to react with LAH in tetrahydrofurane. ${ }^{8}$ In contrast, this reaction proceeds via clearly detectable vinylic organometallic intermediates to $\beta$-allenic alcohols.

For a hypothetical organometallic intermediate there should be two possible modes of elimination, which are depicted as 4 and 5 and which are suggestive of the anti and syn modes of $\beta$-elimination ${ }^{9-12}$ respectively, terms which, however, refer to the relative positions of groups, when they are eliminated from a stable molecule. 
Drawings, such as 4 and 5 , also give a clear indication why the reaction is stereoselective, though they cannot explain the reason why the formation of 4-alken-1-ols is more stereoselective than that of 3-alken-1-ols ( $c f .3 a$ and $3 b)$.

When speculating about the mechanism it is interesting to note the resemblance of the above new trans alkenol synthesis to some other more or less stereoselective formations of these products, which also proceed via elimination of an alkoxy group from an organometallic intermediate or via carbanionic transition states. ${ }^{2,13-22}$

One example of the reaction dealt with in this paper has actually been reported by other authors but was not applied to stereoselective synthesis. LAH reduction of 3,4-diphenyl-4methoxy-2-cyclopenten-1-one gave 3,4-diphenyl3-cyclopenten-1-ol in good yield. ${ }^{22}$

As indicated in Table 1 the yields of 4-alken1-ols in the above reactions of 5-alkoxy-3penten-1-ols with LAH are variable and they are also poorly reproducible $( \pm 15 \%$ yield $)$. However, because of the high stereoselectivity of the reaction it can be concluded that it should in some cases be useful for preparing trans 4alken-1-ols.

\section{EXPERIMENTAL}

Infrared spectra were recorded on a PerkinElmer 15G spectrophotometer as a film between $\mathrm{NaCl}$ discs. NMR spectra were taken on solutions in $\mathrm{CDCl}_{3}$ with tetramethylsilane as an internal standard, using a Perkin-Elmer R 12 B or a Varian HA 100 D spectrometer.

All reactions with Grignard reagents and LiAlH $_{4}$ were performed under nitrogen.

4-Alken-1-ols $(3 b-f)$ and 3-penten-1-ol $(3 a)$. General procedure. The acetylenes $(1 a-f)(0.02$ mol) were hydrogenated in hexane over Lindlar catalyst (Fluka) at atmospheric pressure until the calculated volumes of hydrogen were adsorbed $(1-3 h)$ to give the corresponding olefinic alcohols $(2 a-f)$. The catalyst was filtered off and the solvent evaporated. The residue was dissolved in $15 \mathrm{ml}$ of dioxane and slowly added dropwise to a stirred suspension of $\mathrm{LiAlH}_{4}(0.03$ mol) in dioxane. Note: It is important to allow complete alcoholate formation between $\mathrm{LiAlH}_{4}$ and the alcohol before heating is started as otherwise a violent reaction may occur. After refluxing the reaction mixture was cautiously poured on ice and ether. The alcohol was taken up in ether, which was washed once with a saturated ammonium chloride solution and dried over potassium carbonate. Microdistillation or preparative GLC yielded the title compounds in states of purity exceeding $96 \%$ on GLC.

2-Methyl-trans-5-octen-2-ol (3e) was isolated by preparative GLC (Carbowax $20 \mathrm{M}$ ). IR: 965 $\mathrm{cm}^{-1}(\mathrm{HC}=\mathrm{CH}$, trans $) . \mathrm{NMR}: \delta 5.60-5.40(\mathrm{~m}$, $2 \mathrm{H}), 2.30-1.75(\mathrm{~m}, 5 \mathrm{H}), 1.50(\mathrm{t}, 2 \mathrm{H}), 1.20$ $(\mathrm{s}, 6 \mathrm{H}), 0.97(t, 3 \mathrm{H})$. (Found: $\mathrm{C} 75.7$; H 12.6. Calc. for $\mathrm{C}_{9} \mathrm{H}_{18} \mathrm{O}: \mathrm{C} 76.02 ; \mathrm{H} \mathrm{12.76)}$.

6-Methyl-5-octen-2-ol (3f) was isolated by microdistillation at an oil-bath temperature of $95{ }^{\circ} \mathrm{C}$ and a pressure of $11 \mathrm{mmHg}$. NMR: $\delta$ 5.35-5.05 (m, l H), 3.80 (sextet, $1 \mathrm{H}), 2.80$ $(\mathrm{s}, 1 \mathrm{H}), 2.30-1.75(\mathrm{~m}, 4 \mathrm{H}), 1.65(\mathrm{~m}, 3 \mathrm{H})$, $1.50(\mathrm{q}, 2 \mathrm{H}), 1.20(\mathrm{~d}, 3 \mathrm{H})$ and $0.96(t, 3 \mathrm{H})$. The multiplet at $\delta 1.65$ could be resolved at $100 \mathrm{MHz}$ into a downfield multiplet and an upfield singlet, the latter interfering with the methylene quartet. Rel. areas 2:3. (Found: C 75.9; $\mathrm{H}$ 12.7. Calc. for $\mathrm{C}_{9} \mathrm{H}_{18} \mathrm{O}: \mathrm{C} 76.02 ; \mathrm{H}$ 12.76).

Acknowledgement. I wish to thank Dr. Conny Bogentoft for valuable discussions and most stimulating co-operation, Professors Bruce Rickborn and Manfred Schlosser for their courtesy of making important comments. Furthermore, I am indebted to Professor Bengt Danielsson for commenting upon the manuscript, to my coworker Dr. Lars-Inge Olsson for preparing some of the starting acetylenes and to Mr. Rolf Andersson, Agricultural College of Sweden, for recording the $100 \mathrm{MHz}$ NMR spectrum. This work has been supported financially by the Swedish Natural Science Research Council.

\section{REFERENCES}

1. Claesson, A. and Bogentoft, C. Synthesis (1973) 539.

2. Crombie, L. and Harper, S. H. J. Chem. Soc. (1950) 1707.

3. Crombie, L. and Harper, S. H. J. Chem. Soc. (1950) 873.

4. Brandsma, L. Preparative Acetylenic Chemistry, Elsevier, Amsterdam 1971.

5. Ohno, M. and Hatanaka, A. Bull. Inst. Chem. Res. Kyoto Univ. 42 (1964) 232.

6. Faulkner, D. J. Synthesis (1971) 175.

7. Borden, W. T. J. Amer. Chem. Soc. 92 (1970) 4898

8. Olsson, L.-I., Claesson, A. and Bogentoft, C. Acta Chem. Scand. B 28 (1974) 765.

9. Schlosser, M. In Houben-Weyl, Methoden der Organischen Chemie, Georg Thieme Verlag, Stuttgart 1972, Band 5/1b, p. 9.

10. Sicher, J. Angew. Chem. 84 (1972) 177.

11. Závada, J., Pánková, M., Svoboda, M. and Schlosser, M. Chem. Commun. (1973) 168.

12. Schlosser, M., Gérald, J., Byrne, E. and Sicher, J. Helv. Chim. Acta 56 (1973) 1630. 
13. Cope, A. C. and Heeren, J. K. J. Amer. Chem. Soc. 87 (1965) 3125.

14. Thummel, R. P. and Rickborn, B. J. Amer. Chem. Soc. 92 (1970) 2064.

15. Letsinger, R. L. and Bobko, E. J. Amer. Chem. Soc. 75 (1953) 2649.

16. Martel, J., Toromanoff, E., Mathieu, J. and Nomine, G. Tetrahedron Lett. (1972) 1491.

17. Pattison, F. L. M. and Dear, R. E. A. Can. J. Chem. 41 (1963) 2600.

18. Ansell, M. F. and Gadsby, B. J. Chem. Soc. (1958) 3388.

19. Crombie, L. and Harper, S. H. J. Chem. Soc. (1950) 1714.

20. Julia, M. and Noël, Y. Bull. Soc. Chim. Fr. (1968) 3749.

21. Schlosser, M. In Ref. 9, p. 212.

22. Rio, G. and Charif, M. Bull. Soc. Chim. Fr. (1970) 3593.

23. Landor, P. D., Landor, S. R. and Pepper, E. S. J. Chem. Soc. C (1967) 185.

Received May 7, 1974. 